\title{
OVERVIEW OF MIXED MEANS, OPERATOR NORMS OF AVERAGING OPERATORS AND MAXIMAL FUNCTIONS, AND SOME NEW RESULTS
}

\author{
IVAN PERIĆ
}

\begin{abstract}
We overview the so-called mixed-means inequalities, that is, inequalities for mixed power means for averaging operators which average functions over several scaled families of subsets of $\mathbb{R}^{n}$, such as rectangles, balls, spheres and similar. A general case of such inequalities related to rectangles with sides parallel to coordinate hyperplanes and ellipsoids centered at the origin is proved. Motivation for considering these families can be found in considering collection of subsets of $\mathbb{R}^{n}$ which differentiate suitable functions on $\mathbb{R}^{n}$. Guided by this motivation we distinguish centered and uncentered cases. As a direct consequence of the obtained mixed-means inequalities, the Hardy type inequalities, that is, the operator norms of the averaging operators on $L^{p}$ spaces are deduced. An interesting and important feature of these norms is that they are lower bounds for operator norms of appropriate maximal functions. Further, they can give asymptotic behavior of the operator norms of maximal functions for large $n$ and fixed $p>1$.
\end{abstract}

Mathematics subject classification (2000): 26D10, 26D15.

Keywords and phrases: Integral power means, mixed-means inequalities, averaging operators, scaled family of rectangles, balls, spheres, Hardy's inequality, maximal functions, lower bounds for operator norms.

\section{REFERENCES}

[1] M. Christ And L. Grafakos, Best constants for two nonconvolution inequalities, Proc. Amer. Math. Soc., 123, 6 (1995), 1687-1693.

[2] A. ČIŽMEŠIJA AND J. PeČARIĆ, Mixed means and Hardy's inequality, Math. Inequal. Appl., 1, 4 (1998), 491-506.

[3] A. ČIŽMEŠIJA And J. PeČARIĆ, Classical Hardy's and Carleman's inequalities and mixed means, Survey on Classical Inequalities (Ed. T. M. Rassias), Kluwer Academic Publishers, Netherlands, 2000, $27-65$.

[4] A. ČIŽMEŠIJA AND J. PEČARIĆ, Multivariable mixed means and inequalities of Hardy and LevinCochran-Lee type, Math. Inequal. Appl., 5, 3 (2002), 397-415.

[5] A. ČǏ́mešiJa, J. PeČArić, And I. Perić, Mixed means and inequalities of Hardy and LevinCochran-Lee type for multidimensional balls, Proc. Amer. Math. Soc., 128, 9 (2000), 2543-2552.

[6] A. ČIŽMEŠIJA, I. PERIĆ, Mixed means over balls and annuli and lower bounds for operator norms of maximal functions, J. Math. Anal. Appl., 291 (2004), 625-637.

[7] R. Dror, S. Ganguli, R. S. Strichartz, A search for best constants in the. Hardy-Littlewood maximal theorem, J. Fourier Anal. Appl., 2 (1996), 473-486.

[8] L. Grafakos, S. Montgomery-SMith, Best constants for uncentered maximal functions, Bull. London Math. Soc., 29 (1997), 60-64.

[9] G. Hardy, J. E. Littlewood, And G. Polya, Inequalities, 2nd edition, Cambridge University Press, Cambridge, 1967.

[10] E. H. Lieb AND M. Loss, Analysis, Graduate Studies in Mathematics, Vol. 14, Amer. Math. Soc., Providence, RI, 1997.

[11] D. S. Mitrinović, J. E. PeČARIĆ, And A. M. FinK, Inequalities Involving Functions and their Integrals and Derivatives, Kluwer Academic Publishers, Dordrecht, Boston, London, 1991.

[12] I. PERIĆ, Mixed means for centered and uncentered averaging operators over spheres and related results, BJMA, 2, 2 (2008), 150-162. 
[13] E. M. SteIn, Harmonic analysis: Real-Variable Methods, Orthogonality, and Oscillatory Integrals, Princeton University Press, Princeton, NJ, 1993.

[14] E. M. STEIN, G. WEISS, Introduction to Fourier analysis on Euclidean spaces, Princeton University Press, Princeton, NJ, 1971. 